\title{
Severe opioid withdrawal syndrome after a single dose of nalmefene
}

\author{
Nadine Donnerstag ${ }^{1}$ - Tobias Schneider ${ }^{1}$ Adrian Lüthi ${ }^{1}$ Anne Taegtmeyer ${ }^{2}$. \\ Alexandra Raetz Bravo ${ }^{2}$. Annekathrin Mehlig $^{3}$ (i)
}

Received: 16 April 2015 / Accepted: 2 June 2015 / Published online: 7 June 2015

(C) Springer-Verlag Berlin Heidelberg 2015

\section{Dear Editor,}

We would like to present two case reports of severe opioid withdrawal due to drug-drug interaction between the recently approved opioid antagonist nalmefene and opioid in a context of addiction of codeine, respectively methadone.

Case 1 A 43-year-old man was brought by ambulance to the emergency department (ED) with severe agitation and clinical signs of severe opioid withdrawal approximately $2 \mathrm{~h}$ after a single dose of nalmefene (Selincro ${ }^{\circledR}$, Lundbeck (Switzerland)) for his alcohol dependence. His medical history included paranoid schizophrenia, depression, and alcohol and codeine dependence. He consumed up to two bottles of Makatussin ${ }^{\circledR}$ Hustentropfen (Gebropharma AG, Liestal, Switzerland), a codeine-containing cough medicine, per day (equivalent to $636 \mathrm{mg}$ codeine base per day). The psychiatrist who prescribed the nalmefene was unaware of the extent of the patient's codeine abuse.

The patient needed high bolus doses of midazolam (cumulative dose $25 \mathrm{mg}$, commenced in the community prior to transfer to the ED), morphine (10 mg), and propofol (40 mg) to treat the agitation. He was transferred to the intensive care unit (ICU) for further monitoring and treatment, where he

Annekathrin Mehlig

annekathrin.mehlig@ksbl.ch

1 Department of Anaesthesiology, Kantonsspital Baselland, Liestal, Switzerland

2 Department of Clinical Pharmacology \& Toxicology, University Hospital and Regional Pharmacovigilance Centre, Basel, Switzerland

3 University Clinic of Internal Medicine, Kantonsspital Baselland, University of Basel, Rheinstrasse 26, CH-4410 Liestal, Switzerland received midazolam, propofol, morphine, and clonidine by continuous intravenous infusion. After the first $12 \mathrm{~h}$, it was possible to withdraw clonidine and propofol; however, midazolam and morphine were continued for a further $48 \mathrm{~h}$. Attempts to stop the medication before this point resulted in reemergence of the opioid withdrawal symptoms.

After 3 days of ICU treatment, we were able to transfer the patient to psychiatric inpatient services.

Case 2 A 55-year-old patient with polysubstance abuse on a methadone maintenance programme asked his general practitioner to prescribe him nalmefene to reduce his alcohol consumption after he had seen a television report about it the night before. He presented to the ED with severe symptoms of opioid withdrawal a few hours after taking two tablets of nalmefene $(32 \mathrm{mg}$ in total) for the first time. He was treated for 3 days with midazolam, morphine, clonidine, and propofol as this management approach had been successful in the case described above (which had presented to our ED 10 days earlier). As seen in the first case, attempts to reduce the medication prior to 3 days after dosing with nalmefene led to an increase of the opioid withdrawal symptoms on each occasion. After 3 days of ICU treatment, the patient could be transferred to a general ward.

Both cases were reported anonymously according to national law within 15 days to the Swiss medicines regulatory authorities (Swissmedic) as serious adverse drug reactions resulting from a drug-drug interaction.

Nalmefene is an opioid antagonist with high affinity for $\mu$, $\delta$, and $\kappa$ receptors [1]. It was approved in Europe in February 2013 and in Switzerland in April 2014 for the reduction of alcohol consumption in adult patients with alcohol dependence [2]. Alcohol consumption stimulates the endogenous release of opioids, which binds to $\mu$ and $\delta$ receptors. It thereby increases the release of dopamine in the nucleus accumbens, 
which induces reward and positive reinforcement effects. Antagonists such as nalmefene reduce the positive reward effect of alcohol. Nalmefene is rapidly absorbed after oral administration with a peak plasma concentration 90 min after ingestion [3]. Its mean plasma half-life is $12 \mathrm{~h}$ [4]. However, the occupancy of the opioid receptor lasts much longer with a high nalmefene occupancy rate of $83-100 \%$ persisting beyond $26 \mathrm{~h}$ [4]. The duration of blockade varies according to the method used to measure it and the dose of nalmefene and can be as long as $72 \mathrm{~h}[1,5]$. Due to its effective opioid antagonism and its long duration of action, nalmefene was approved in the USA in 1995 for the complete or partial reversal of opioid drug effects, including respiratory depression and reversal of known or suspected opioid overdose [6]. The administration of nalmefene is contraindicated in patients who are dependent on opioids and patients experiencing acute opioid withdrawal syndrome [2].

To avoid severe opioid withdrawal syndromes such as occurred in the cases we present here, we recommend that in addition to taking a detailed medical history (which includes asking about substance and specifically codeine abuse), a toxicological screen be performed prior to starting therapy with nalmefene. It is imperative that prescribers strictly comply with the labelled contraindication of opioid abuse.

\section{References}

1. Jones HE, Johnson RE, Fudala PJ, Henningfield JE, Heishman SJ (2000) Nalmefene: blockade of intravenous morphine challenge effects in opioid abusing humans. Drug Alcohol Depend 60:29-37

2. Product Information Selincro, Lundbeck (Schweiz) AG, Opfikon, Switzerland (2014) Available at http://compendium.ch/prod/ selincro-filmtabl-18-mg-ih-07-14-/de

3. Paille F, Martini H (2014) Nalmefene: a new approach to the treatment of alcohol dependence. Subst Abuse Rehabil 5:87-94

4. Ingman K, Hagelberg N, Aalto S, Nagren K, Juhakoski A, Karhuvaara S, Kallio A, Oikonen V, Hiertala J, Scheinin H (2005) Prolonged central $\mu$-opioid receptor occupancy after single and repeated nalmefene dosing. Neuropsychopharmacology 12:22452253

5. Wang DS, Sternbach G, Varon J (1998) Nalmefene: a long-acting opioid antagonist. Clinical applications in emergency medicine. J Emerg Med 16:471-475

6. Product information Revex, Baxter Deerfield Illinois, USA, 2006; Available at http://www.accessdata.fda.gov/scripts/cder/drugsatfda/ index.cfm 